\title{
Clinical evidence for heterogeneity in myotonic dystrophy
}

\author{
SARAH BUNDEY
}

From the Department of Clinical Genetics, Birmingham Maternity Hospital, Birmingham B15 2 TG.

SUMMARY In a study of 35 index patients who developed myotonic dystrophy between birth and 30 years (neonatal cases were excluded), 30 could be categorised into two clinical types. The 13 type 1 patients had a more severe limb weakness, of patchy distribution, associated with proportional facial weakness. The 17 type 2 patients had a milder and more diffuse limb weakness; their facial weakness, however, was very pronounced and preceded the limb weakness by several years. All but one of the 25 affected relatives who were examined belonged to the same category as their index relative, providing evidence that the cause of the clinical heterogeneity was genetic. Subsequent observations showed that mental retardation, male infertility, and neonatally affected offspring were commoner in type 2 patients.

Congenital myotonic dystrophy could occur among the offspring of either affected males or affected females, but neonatal symptoms were confined to the offspring of affected women. The overall risk for having neonatally affected offspring for this prospective study of young adult patients was 7 in 38, and for the offspring of affected females 7 in 27 . The risk for having a surviving child whose mental or physical handicap or both required special schooling was 1 in 12 for males and 4 in 27 for females.

Myotonic dystrophy is an autosomal dominant disorder, with manifestations ranging from a baby affected at birth who is both mentally and physically handicapped to an adult with lenticular opacities only. In order to give helpful genetic counselling to patients it is useful to know the risk of having a severely affected child, since this is clearly of more concern to a family than the risk of recurrence of an adult onset disorder.

In this study I have made a distinction between babies with neonatal symptoms and those who have no neonatal symptoms but who are clearly congenitally affected because they have talipes equinovarus at birth. I have done this because the neonatal form of the disease is often so dramatic, with severe respiratory problems, even apnoea, at birth and with natural improvement if the baby survives. The temporary nature of these symptoms, and their invariable occurrence in offspring of affected mothers, leads one to postulate a mechanism akin to transitory neonatal myasthenia.

Previous studies ${ }^{1-4}$ have shown that neonatal myotonic dystrophy occurs among the offspring of females who have an unusually early distribution of Received for publication 17 February 1982. ages of onset, for such females nearly always have signs of disease at the time of their pregnancies, although the mean age of onset of disease in randomly selected patients is about 30 years. $^{5}$ Other points arising out of these studies of neonatal cases are that the risk of recurrence of neonatal myotonic dystrophy after the first case is high ${ }^{4}$ and is found not only for further offspring of an affected mother, but also for the offspring of her affected sisters. ${ }^{6}$ It is also clear that only a proportion of female patients who develop myotonic dystrophy before, say, the age of 30 have children with the neonatal form of the disease. In other words, some affected females and their sisters appear to be at high risk, while other affected females do not.

It was therefore planned to study the empirical risks for congenital disease, with or without neonatal symptoms, among the offspring of both male and female patients who themselves had onset of disease before the age of 30 years. It was also planned to see if it was possible to identify those patients who had a higher than usual risk of having a congenitally affected child. Such possible methods of identification included a clinical assessment of measurement of immunoglobulin levels (since in a previous study 
the greatest lowering of IgG was found in the families where there were congenital cases $^{5}$ ). It was also planned to observe the fertility of the index patients, and in conjunction with these observations, estimations were made of the levels of follicular stimulating hormone (FSH), luteinising hormone $(\mathrm{LH})$, and testosterone in male patients.

Once the study was commenced it became clear that there were clinical differences between the index patients. The study was therefore extended to see if these clinical differences represented genetic heterogeneity.

\section{Methods}

A search was made for patients who had developed, by the age of 30 , symptoms which ultimately led to a neurological consultation. All neurologists in the West Midlands were asked for names of patients; names of patients were also found in the in-patient diagnostic indices of the five general hospitals, one neurological hospital, and one children's hospital of the Birmingham Area Health Authority; in the inpatient diagnostic index of the Coventry and Warwickshire Hospital; in the diagnostic index (covering both in-patients and out-patients) of the Neurological Department of the North Staffordshire Royal Infirmary; in the records of the Department of Clinical Genetics; and finally in the records of the three electrodiagnostic units in Birmingham.

All patients ascertained had had their diagnosis confirmed by a consultant neurologist on the basis of a muscular dystrophy (affecting the face as well as limbs), myotonia on clinical examination as well as on electromyography, and, in most cases, other features such as testicular atrophy and lenticular opacities. The medical records of the patients were scrutinised, and patients were excluded if they had onset after the age of 30 ( 50 patients) or if they were ascertained solely because they had an affected relative. Ten patients with neonatal myotonic dystrophy, two patients with congenital onset and no neonatal symptoms, and two patients with childhood onset were excluded because they were still children. These 14 patients could not supply information on the risks to offspring. Moreover, it was felt that the ten neonatal patients could not be considered representative of myotonic dystrophy patients in general, because of the possibility of an intrauterine factor affecting their presentation and subsequent development. ${ }^{12}$

A total of 48 names of patients with symptoms of myotonic dystrophy before the age of 30 was thus obtained (table 1). Permission to approach the patients was received from the consultants and general practitioners concerned. However, 13
TABLE 1 Ascertainment of index patients.

\begin{tabular}{lcc}
\hline & $\begin{array}{l}\text { Patients in } \\
\text { study }\end{array}$ & $\begin{array}{l}\text { Patients not } \\
\text { seen }\end{array}$ \\
\hline Hospital IP diagnostic indices & 18 & 3 \\
IP and OP diagnostic indices of & & \\
two neurologists and one & 13 & 10 \\
neurological department & 1 & 0 \\
Reports of electromyograms & 3 & 0 \\
Genetic clinic records & & \\
\hline
\end{tabular}

patients could not be visited since seven had died, two had moved out of the West Midlands, three could not be traced, and one refused. There were thus 35 patients in the study, of whom 18 were males and 17 were females.

These patients were visited in their homes; they were asked about the way in which their illness had developed, they were examined, and a family history was taken. Where permission was granted, blood was taken for immunoglobulin levels, and, from males, for FSH, LH, and testosterone estimations. An attempt was made to visit and examine available and affected relatives. Where reportedly affected relatives had died, or where there was a history of stillbirth or a neonatal death, an effort was made to see their medical records.

At the time of the initial interview the patients were categorised according to the distribution and severity of their muscle weakness into one of two groups. The clinical group designated as type 1 myotonic dystrophy most closely resembles the classical myotonic dystrophy of Steinart, Thomasen, ${ }^{7}$ and Batten and Gibb, ${ }^{8}$ where the muscle weakness in the limbs has a characteristic distribution affecting particularly the triceps, brachoradialis, and quadriceps femoris muscles. The accompanying facial weakness is in proportion to the limb weakness. In patients designated as having type 2 myotonic dystrophy, their facial weakness was more marked than the limb weakness and preceded the symptoms of limb weakness by several years. The limb weakness was often of patchy distribution, but could be mild and diffuse. The categorisation of an individual patient which was made at his or her home was never subsequently changed. Observations were made at a later date on the types of myotonic dystrophy separately concerning their other clinical manifestations, such as mental retardation, infertility, the outcomes of pregnancies, and the segregation ratios in their families.

After the main study was completed an attempt was made to visit the affected parents of the ten excluded neonatal cases to see what type of myotonic dystrophy they had. Four mothers could not be visited (two were untraced, one refused to cooperate, and one lived too far away). Six affected mothers were visited and categorised. 


\section{Results}

The 35 index patients consisted of 18 males and 17 females aged 24 to 54 years with a mean age of 39.1. All but five were allocated because of the distribution or relative severity of muscle weakness into one of the two groups described above. Thirteen index patients (seven males and six females) were classified as having type 1 myotonic dystrophy and 17 index patients (nine males and eight females) were classified as having type 2 myotonic dystrophy. Three of the five patients who were not classified had had their symptoms for 16, 20, and 36 years respectively, and had severe widespread involvement so that classification was impossible. One patient had a mild generalised weakness without distinctive features, and one patient (an Indian without a family history) had presented within 4 years of his first symptoms of limb weakness. The weakness was patchy and this, together with his presentation, suggested type 1 , yet he had severe facial weakness and dysarthria, suggesting type 2 myotonic dystrophy.

\section{CLINICAL OBSERVATIONS ACCORDING TO CATEGORY OF INDEX PATIENT}

The ages of onset of the 35 index patients are shown in fig 1 . Three patients had congenital onset (demonstrated by the presence of talipes equinovarus at birth). The onset in three patients who were sufficiently mentally retarded to require special education is difficult to date and they have been placed in the 2 to 5 year age group, but possibly should be considered to have congenital onset. The remaining patients had onset of symptoms clearly dated between birth and 30 years.

A bimodality can be seen in fig 1 , with one mode of onset before the age of 5 years and a second mode

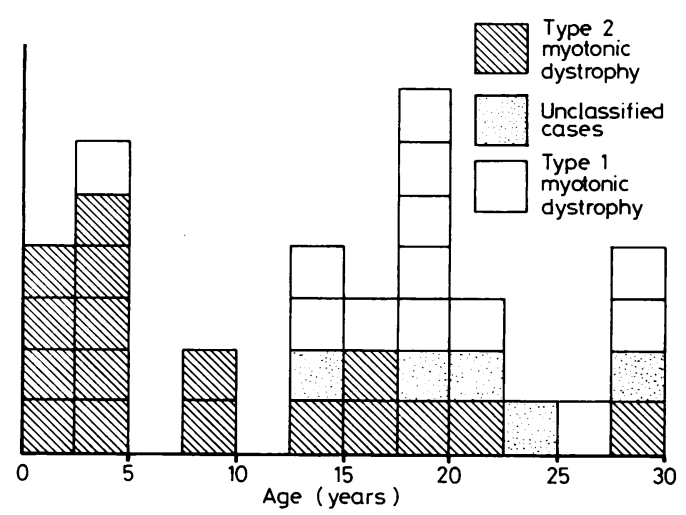

FIG 135 patients with onset of myotonic dystrophy under the age of 30 (excluding neonatal cases). between 13 and 22 years. There is possibly a third mode of onset between 27 and 30 years. Most of the patients in the early peak have type 2 myotonic dystrophy and most in the second peak have type 1 myotonic dystrophy.

The mean age of onset for type 2 patients was 9.5 years with half of them developing symptoms before entering school. The mean age of onset for type 1 patients was 18.9 years.

The presenting symptoms of the 35 index patients are given in table 2 and divided by type and sex. Although the numbers are small, it is worth noting that all patients who presented with frequent falls because of localised weakness of the quadriceps femoris muscle were either type 1 or were unclassified; that all patients with congenital talipes or mental retardation were classified as type 2 ; and that four of the 17 male index patients first presented because of infertility or impotence. One female also complained of infertility but this was not her presenting complaint.

Weakness of limb muscles was divided into mild (just discernible on neurological examination), severe (causing considerable difficulty in carrying out everyday activities), and moderate (all intervening degrees of severity). No type 1 patient had mild weakness when seen, in contrast to five type 2 patients, who had already lost their tendon reflexes at the time their limb weakness was mild.

Overall, the weakness of type 1 patients was more severe than that of type 2 patients. Of ten type 1 patients who had symptoms for less than 20 years, six had severe disability, compared to only one of 11 type 2 patients. The mean duration of illness for the 13 type 1 patients was 22.5 years, compared to 27.4 years for the type 2 patients. Moreover, if only the patients with severe weakness are considered, the eight type 1 patients had a mean duration of illness of 24 years, whereas the six severely affected type 2 patients had a mean duration of 41 years.

The interval between first symptom and first seeking medical attention was longer for type 2 patients than for type 1 patients: 14.9 years compared to $11 \cdot 2$ years. Of the eight patients who waited

TABLE 2 The manifestation of myotonic dystrophy which first took the patient to see a doctor.

\begin{tabular}{llll}
\hline Symptom & Type 1 & Type 2 & Unclassified \\
\hline Frequent falls & 4 & 0 & 1 \\
Other type of weakness & 3 & 6 & 2 \\
Myotonia & 4 & 1 & 1 \\
Congenital talipes & 0 & 3 & 0 \\
Mental deficiency & 0 & 3 & 0 \\
Paranoia & 1 & 0 & 0 \\
Infertility \pm impotence & 1 & 2 & 1 \\
Cataract & 0 & 1 & 0 \\
Heart attack & 0 & 1 & 0 \\
\hline
\end{tabular}


for 20 years or more before going to their doctor, six had type 2 disease. Nine of the 13 type 1 patients were referred directly to a neurologist because of their symptoms, and the mean interval between first symptom and referral was $9 \cdot 1$ years. In contrast, only six of the 17 type 2 patients were directly referred to a neurologist and the mean interval between first symptom and referral was $16 \cdot 3$ years.

TABLE 3 Fertility of index patients.

\begin{tabular}{lccll}
\hline & $\begin{array}{l}\text { No of } \\
\text { patients }\end{array}$ & $\begin{array}{l}\text { No of } \\
\text { children } \\
\text { surviving } \\
\text { infancy }\end{array}$ & $\begin{array}{l}\text { No of } \\
\text { neonatal } \\
\text { deaths }\end{array}$ & $\begin{array}{l}\text { Mean } \\
\text { number of } \\
\text { children } \\
\text { per patient }\end{array}$ \\
\hline Type 1 males & 7 & 7 & 0 & 1.0 \\
Type 2 males & 9 & 3 & 0 & $0 \cdot 3$ \\
Unclassified males & 2 & 1 & 0 & 0.5 \\
All males & 18 & 11 & 0 & 0.6 \\
Type 1 females & 6 & 4 & 2 & 1.0 \\
Type 2 females & 8 & $12^{*}$ & 2 & 1.8 \\
Unclassified females & 3 & 7 & 1 & 2.7 \\
All females & 17 & 23 & 5 & 1.6 \\
\hline
\end{tabular}

*Includes one pair of affected monozygotic twins, counted as one child.
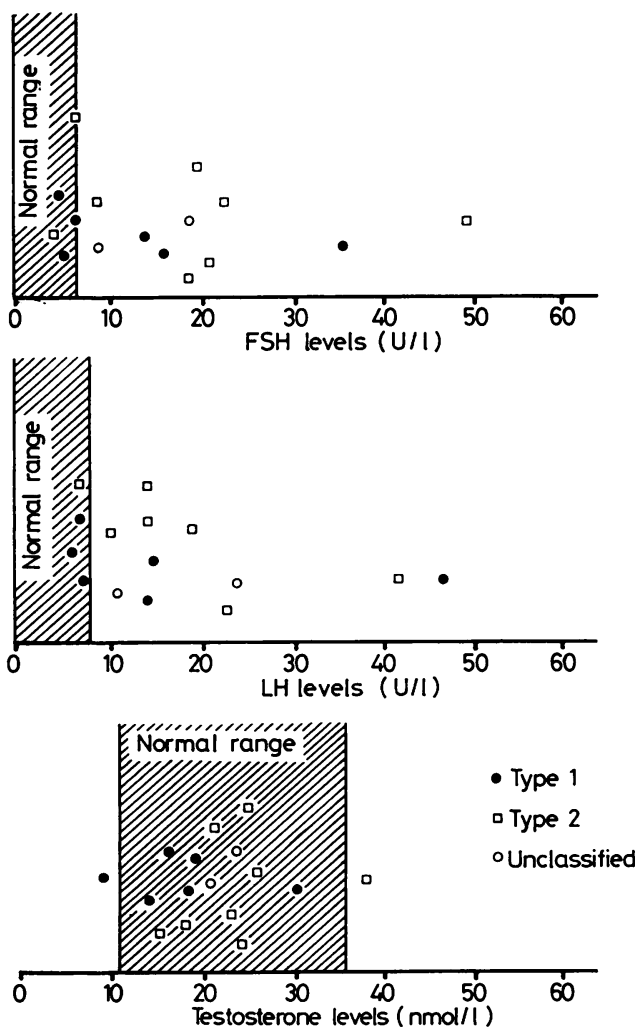

FIG 2 Endocrine studies in male patients with myotonic dystrophy.
FER TILITY OF INDEX PATIENTS

The 35 index patients had between them only 39 children, which is about half that expected from population data. However, the infertility was not evenly distributed (table 3 ). The most fertile were the type 2 females, with an overall fertility (measured as mean number of children per patient) of $1 \cdot 8$. In contrast, the least fertile were the type 2 males with an overall fertility of $\mathbf{0 \cdot 3}$.

ENDOCRINE AND IMMUNOLOGICAL STUDIES The FSH, LH, and testosterone levels are presented in fig 2. Only five of the 16 male patients tested had levels of FSH that were within the normal range and only four had normal levels of LH. In contrast, all but two patients had normal levels of testosterone, and the outliers, with levels of 9 and $38 \mathrm{nmol} / 1$ were only just outside the normal range.

Type 2 patients tended to have higher levels of FSH and LH compared to type 1 males. The results were, respectively, $19 \cdot 1 \mathrm{U} / 1$ and $18.5 \mathrm{U} / 1$, compared to $13.8 \mathrm{U} / 1$ and $15.7 \mathrm{U} / 1$ for type 1 patients. Testosterone levels were also slightly higher in type 2 patients, with a mean of $23.8 \mathrm{nmol} / 1$, compared to $17.7 \mathrm{nmol} / 1$ for type 1 patients.

The distribution of IgG levels was lower than normal for the index patients and is displayed in fig 3. Nine patients had levels below the normal range, and all but four of the remaining patients were in the lower half of the normal range. No difference in mean level or distribution was noted between type 1 and type 2 patients. The distributions of IgA and IgM levels were quite normal, with again no difference between type 1 and type 2 patients.

\section{FAM ILY DATA}

Although all available relatives who were reported to be affected were visited, only 40 of 152 reportedly healthy first degree relatives were seen. Since patients with myotonic dystrophy may be without symptoms at the time they have signs of the disease, it is probable that the segregation ratios shown in table $\mathbf{4}$ are underestimates. However, the proportions of affected relatives are consistent with dominant inheritance of a disease that has variable onset age and variable manifestation. It is interesting that the segregation ratios are higher for type 2 patients than for type 1 ; presumably this is because of the lower onset age in type 2 myotonic dystrophy.

Few parents were available for visiting, but of the total of $70,25(0.36)$ were certainly or reportedly affected with either cataracts or neurological symptoms or both. There were ten parental couples where neither member had symptoms of disease, and in one of these both partners were without signs of disease, clinically and on electromyography and slit 


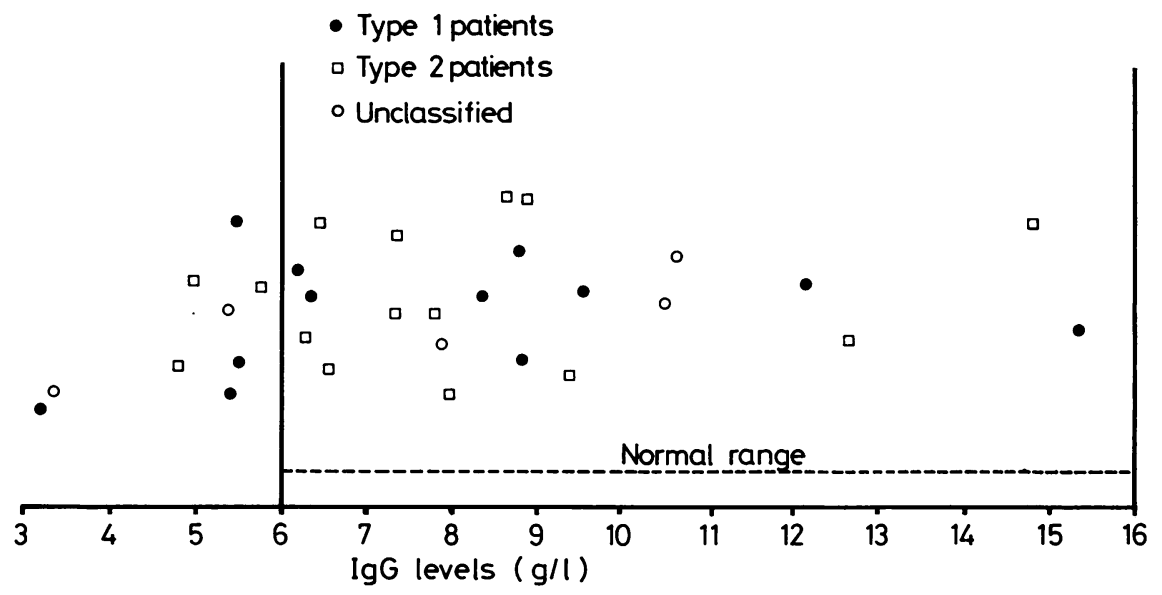

FIG 3 IgG levels in patients with myotonic dystrophy.

TABLE 4 Proportions of relatives known to be affected. Numbers of affected/total relatives (proportions given in parentheses).

\begin{tabular}{|c|c|c|c|}
\hline & Parents & Sibs & Children \\
\hline $\begin{array}{l}\text { Type } 1 \\
\text { index patients }\end{array}$ & $10 / 26(0 \cdot 38)$ & $6 / 34(0 \cdot 18)$ & $2 / 12^{*}(0 \cdot 17)$ \\
\hline $\begin{array}{l}\text { Type } 2 \\
\text { index patients } \\
\text { Unclassified }\end{array}$ & $11 / 34(0 \cdot 32)$ & $16 / 61(0 \cdot 26)$ & $8 / 17 \dagger(0.47)$ \\
\hline $\begin{array}{l}\text { index patients } \\
\text { All }\end{array}$ & $\begin{array}{r}4 / 10(0 \cdot 40) \\
25 / 70(0 \cdot 36)\end{array}$ & $\begin{array}{r}2 / 13(0 \cdot 15) \\
24 / 108(0 \cdot 22)\end{array}$ & $\begin{array}{r}2 / 9(0.22) \\
12 / 38(0.32)\end{array}$ \\
\hline
\end{tabular}

* Excluding a premature dead baby.

†Counting one set of $\mathrm{MZ}$ twins as one child.

lamp examination. It is therefore probable that their affected child, who was an isolated case, had acquired a new mutation. It is likely that there are other new mutants who could not be identified since their reportedly healthy parents were not available for study. For the type 1 patients, the affected parent was the father in five instances, and the mother in four. For the type 2 patients, the affected parent was the father in six instances and the mother in seven.

The type 2 patients came from larger families; they had a mean of 3.6 sibs per index patient, whereas the type 1 patients had a mean of 2.6 sibs per index patient. Of the 24 affected sibs, only ten could be examined, but reliable information was available for the remainder, of whom ten had died and four lived too far away.

All but four of the living children were examined and medical records confirmed the diagnosis in the two who were reportedly affected but not seen. There were five neonatal deaths. One was diagnosed in life as having neonatal myotonic dystrophy and three were diagnosed in retrospect since their medical notes recorded at least three of the following: hydramnios, hypotonia, failure to establish respirations, or an abnormality of the feet. One neonatal death was considered at the time to be the result of prematurity, a recognised obstetric complication of myotonic dystrophy. However, her mother subsequently had a baby with neonatal myotonic dystrophy and so it is possible that the first premature baby was affected with neonatal disease. Overall, 12 (including four who had died) of the 38 children were affected (table 5). Seven of the 12 had congenital myotonic dystrophy with neonatal symptoms, one was congenitally affected but had no neonatal symptoms, and the remaining four developed symptoms during childhood.

The affected first degree relatives who were seen were classified into type 1 and type 2 according to the criteria used for classifying the index patients (table 6). All the affected sibs belonged to the same category as the index patient, apart from one sib who could not be classified because his illness was too advanced. However, only two affected sibs of type 1 patients could be examined, as three of the remaining four who were affected had died and one was living far

TABLE 5 The offspring of index patients.

\begin{tabular}{|c|c|c|c|c|c|}
\hline & \multicolumn{2}{|c|}{$\begin{array}{l}\text { Neonatal myotonic } \\
\text { dystrophy }\end{array}$} & \multicolumn{2}{|c|}{$\begin{array}{l}\text { Myotonic dystrophy } \\
\text { with onset }\end{array}$} & \multirow[b]{2}{*}{$\begin{array}{l}\text { Healthy } \\
\text { children }\end{array}$} \\
\hline & $\begin{array}{l}\text { Neonatal } \\
\text { death }\end{array}$ & $\begin{array}{l}\text { Living } \\
\text { child }\end{array}$ & At birth & $\begin{array}{l}\text { In child- } \\
\text { hood }\end{array}$ & \\
\hline $\begin{array}{l}\text { Type } 1 \\
\text { index } \\
\text { patients }\end{array}$ & 1 & 0 & 0 & 1 & 10 \\
\hline $\begin{array}{l}\text { Type } 2 \\
\text { index } \\
\text { patients }\end{array}$ & 2 & 2 & 1 & $3^{*}$ & 9 \\
\hline $\begin{array}{l}\text { Unclassified } \\
\text { patients }\end{array}$ & 1 & 1 & 0 & 0 & 7 \\
\hline
\end{tabular}

*A pair of affected MZ twins has been counted as one child. 
TABLE 6 Resemblances between relatives*.

\begin{tabular}{|c|c|c|c|c|c|c|}
\hline & \multicolumn{3}{|c|}{ Affected sibs } & \multicolumn{3}{|c|}{ Affected parents, children, and cousins } \\
\hline & Type 1 & Type 2 & Unclassified & Type 1 & Type 2 & Unclassified \\
\hline $\begin{array}{l}\text { Type } 1 \text { index patients } \\
\text { Type } 2 \text { index patients }\end{array}$ & $\begin{array}{l}2 \\
0\end{array}$ & $\begin{array}{l}0 \\
7\end{array}$ & $\begin{array}{l}0 \\
1\end{array}$ & $\begin{array}{l}2 \\
0\end{array}$ & $\begin{array}{l}1 \\
12\end{array}$ & $\begin{array}{l}0 \\
2\end{array}$ \\
\hline
\end{tabular}

*Excluding relatives with neonatal myotonic dystrophy.

away. All children (that is, excluding neonatally affected cases) and cousins also belonged to the same category as their index patient relative, but one of five parents was classified as type 2 while her two sons were classified as type 1 myotonic dystrophy. Two parents had cataracts only and therefore could not be categorised.

\section{RISKS FOR OFFSPRING}

The total risk for index patients having a child with congenital myotonic dystrophy and superimposed neonatal symptoms (neonatal myotonic dystrophy) was 7 out of 38, excluding the premature dead baby of uncertain status. However, the risks were confined to female patients as seven out of their 27 children had neonatal myotonic dystrophy, an incidence of about 1 in 4 . The risk was greater for type 2 females (four out of 14 affected) than for type 1 females (one out of six affected).

As the mortality rate for neonatal myotonic dystrophy is about $50 \%,{ }^{6}$ and as congenital cases without neonatal symptoms and childhood cases usually survive, it was thought to be useful to know the risks for having a child who survived with mental retardation or physical handicap or both who required special schooling. The observed risks were 1 in 12 for the offspring of affected males and 4 in 27 for the offspring of affected females.

\section{OUTSIDE THE MAIN STUDY}

Once it had been concluded that there were two clinical types of myotonic dystrophy, one with a higher risk than the other for having neonatally affected offspring, it was thought to be of interest to assess the clinical category of the affected parents of the cases of neonatal myotonic dystrophy who had been ascertained through the same sources as the index patients. All affected parents were mothers and six of the ten could be visited. Of these six, one had type 1 myotonic dystrophy, one could not be classified, and three had type 2 myotonic dystrophy. One mother (aged 29) had no signs of myotonic dystrophy and no evidence of it on slit lamp examination or on electromyography. However, she must have carried the gene for type 2 myotonic dystrophy, since two brothers and a paternal cousin, aged 30,18 , and 28 years, were mentally retarded with facial weakness and myotonia, but with no, or only mild, limb weakness.

\section{Discussion}

Genetic heterogeneity in myotonic dystrophy has $\overrightarrow{\vec{\omega}}$ been postulated before, ${ }^{9}$ when high correlation coefficients for ages of onset were observed for pairs of first degree relatives. The correlation coefficient $\vec{\theta}$ for all sib pairs was 0.81 , which was significantly $\dot{*}$ different from $0 \cdot 5$. (If the correlation coefficient $\omega$ had been consistent with 0.5 then the likely explana- $\nexists$ tion would be that the intrafamilial resemblances 욱 were the result of many modifying genes. The fact that the coefficient was significantly greater than $0.5 \bigcirc$ suggested that a different main gene was present in $\frac{0}{0}$ some families.) When the sib pairs belonging to $\underset{\mathbb{D}}{\mathbb{D}}$ index patients who had symptoms at birth or in $\overrightarrow{\vec{C}}$ infancy were removed, the correlation for the $\stackrel{\oplus}{\oplus}$ remaining sib pairs was still above 0.5 at 0.64 , bui $N$ not significantly higher. The correlation coefficient $\square$ dropped below 0.5 to 0.45 once the sib pairs belonging to index patients with onset under 20 were removed, stggesting that there was now homogeneity in the remaining families. Thus there was evidence $\stackrel{\mathbb{\perp}}{\propto}$ for at least two, and possibly three, different main $\underset{\overrightarrow{2}}{\overrightarrow{2}}$ genes for myotonic dystrophy. Grimm ${ }^{10}$ also found $\frac{O}{3}$ a sib-sib correlation coefficient for age of onset that was significantly higher than $0 \cdot 5$, but his interpretation of the data was different. Both Bundey and Carter $^{9}$ and Grimm $^{10}$ found correlation coefficients for ages of onset for parent/index patient and index $\dot{0}$ patient/child pairs that were higher than $0 \cdot 5$, though not significantly so.

As well as this statistical evidence for heterogeneity clinical evidence for heterogeneity in myotonic dys- 0 trophy has come from Labrador. ${ }^{11}$ In this family the patients frequently presented with epiphora and reduced frequency of blinking, the male patients $\underset{\sim}{\mathrm{N}}$ did not suffer from hair loss or testicular atrophy, $\Omega$ the female patients had a high incidence of obstetric $N$ complications, and there was no lowering of IgG levels, but instead a reduction of IgA levels. No patient resembling the Labradorean type of myotonic dystrophy was seen in the present study.

There are two main pieces of evidence for hetero- $\stackrel{\oplus}{+}$ geneity in myotonic dystrophy in the present study. 7 The first is that the age of onset distribution for the $\stackrel{0}{\vec{P}}$

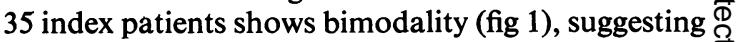
that two entities might be present. The bimodality $\mathbb{Q}$ would be more striking if the six neonatal cases seen 
were included in the figure. The bimodality roughly corresponds to type 1 and type 2 patients.

The second piece of evidence is that the clinical differences which divided 30 of the 35 patients into two groups were reflected in their affected relatives. All but one affected relative (a parent) belonged to the same clinical category as the index patient. The explanation for this exceptional family could be that the mother was incorrectly classified as type 2 or that her two sons were incorrectly classified as type 1. It is difficult to explain the remaining intrafamilial resemblances by a common family environment. I conclude that there is a genetic basis for the observed clinical differences, and in view of the other evidence (high correlation coefficients for ages of onset and bimodality of ages of onset), it is likely that there are different main genes for myotonic dystrophy.

An alternative explanation is that age of onset determines the type of disease that develops. This would be surprising in view of the fact that the earliest onset (excluding cases with superimposed neonatal symptoms) have a milder form of disease. Also, such a hypothesis would not explain either the very high correlation coefficients observed ${ }^{9}$ or the bimodality for age of onset.

Another possible explanation for the clinical heterogeneity is the observation by Harper ${ }^{12}$ that an affected woman appears to influence the severity and onset of disease of her offspring, not only with regard to neonatal affection, but also in relation to onset in childhood. However, in the present series, there was no significant excess of affected mothers of type 2 cases (seven mothers : six fathers). Also, among the parents of probands who developed symptoms before the age of 20 , there were nine mothers and nine fathers.

Once the index patients had been classified into two types on the basis of the distribution and relative severity of muscle weakness, observations could be made on secondary features of the two types of myotonic dystrophy, and these have been summarised in table 7. The association of mental retardation and early loss of reflexes with type 2 myotonic dystrophy raises the possibility of neuronal degeneration in this disorder. The study suggests that type 2 myotonic dystrophy is more common than type 1 myotonic dystrophy, when considering this group of index patients with onset under 30 . However, we do not know the classification of the seven patients who were ascertained but who had died before the outset of the study, and it is possible that the majority of these could have had type 1 disease in view of its greater severity and shorter duration.

The other aim of this study was to observe prospectively the empirical risk for neonatal myotonic dystrophy occurring in the offspring of patients with onset before the age of 30 . The overall risk has been shown to be in 7 in 38, but the risk was confined to the offspring of affected females, 7 out of 27 . Although neonatal symptoms are restricted to the offspring of affected women, congenital myotonic dystrophy without neonatal symptoms may occur among the offspring of both affected males and females. Three index patients in this study had congenital talipes: one had an affected mother, one had an affected father, and for the other it was not known which of the two dead parents was affected, but one of them must have been as the index patient had an affected brother. Mental retardation necessitating education at a special school could be considered a manifestation of congenital onset; the three mentally retarded index patients in the study had two affected mothers and one affected father. The fact that males with type 2 myotonic dystrophy have about one-sixth the fertility of females with type 2 myotonic dystrophy is probably sufficient to account for the fact that congenitally affected patients (with or without neonatal symptoms) are more commonly found to have affected mothers.

TABLE 7 Observations on types of myotonic dystrophy.

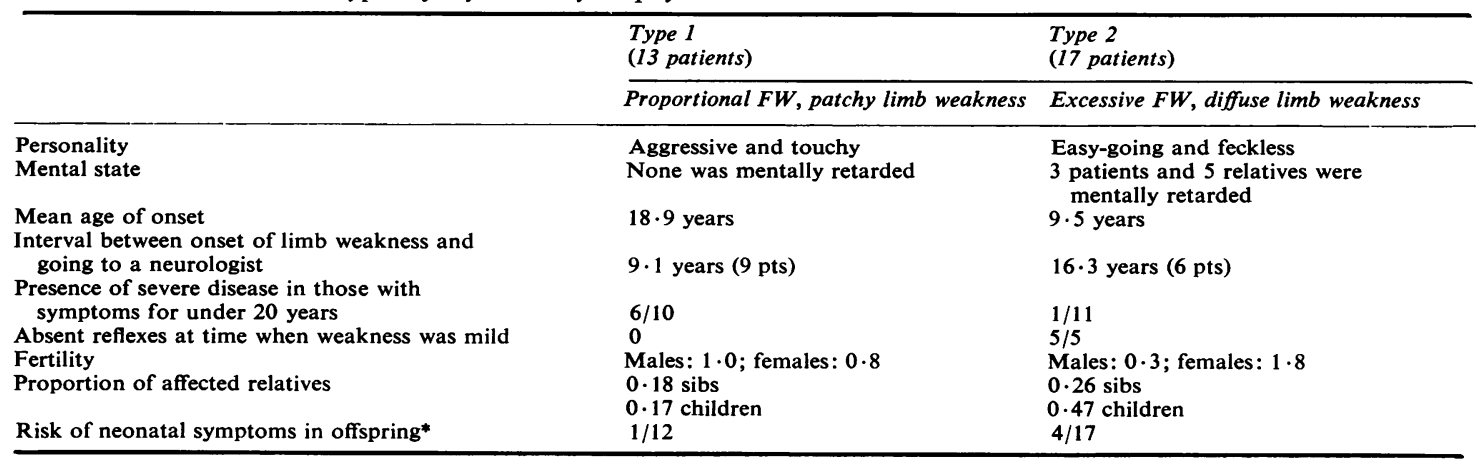

${ }^{*}$ Risk for whole series: 7/39 
However, why some infants with congenital myotonic dystrophy also have severe neonatal symptoms, which carry a $50 \%$ mortality, is not known, although the suggestion that a maternal intrauterine factor is responsible ${ }^{12}$ seems very reasonable.

I am very grateful to the neurologists of the West Midlands for permission to include their patients and I particularly thank Dr E Bickerstaff, Dr D Riddoch, and the neurologists of the North Staffordshire Royal Infirmary for permission to study their diagnostic indices. I am grateful to Dr G Boddie for studying the parents of two patients. I thank Professor R A Thompson's department for their estimations of immunoglobulin levels and $\operatorname{Dr} \mathbf{S} S$ Lynch for estimations of LH, FSH, and testosterone levels. I thank Dr S Green and Dr J Insley for permission to report on the families of their neonatal cases.

\section{References}

1 Harper PS, Dyken PR. Early-onset dystrophia myotonica: evidence supporting a maternal environmental factor. Lancet 1972 ;ii:53-5.
2 Dyken PR, Harper PS. Congenital dystrophia myotonica. Neurology (Minneap) 1973;23:465-73.

3 Harper PS. Congenital myotonic dystrophy in Britain. 1 Clinical aspects. Arch Dis Child 1975;50:505-13.

4 Harper PS. Congenital myotonic dystrophy in Britain. 2 Genetic basis. Arch Dis Child 1975;50:514-21.

5 Bundey S, Carter CO, Soothill JF. Early recognition of heterozygotes for the gene for dystrophia myotonica. J Neurol Neurosurg Psychiatry 1970;33:279-93.

6 Pearse RG, Höweler CJ. Neonatal form of dystrophia myotonica. Arch Dis Child 1979;54:331-8.

7 Thomasen E. Myotoria. Thomsen's disease (myotonia congenita), paramyotonia, and dystrophia myotonica. Denmark: Universitetsforlaget i Aarhus, 1948.

8 Batten FE, Gibb HP. Myotonia atrophica. Brain 1909; 32:187-205.

9 Bundey S, Carter CO. Genetic heterogeneity for dys- $\vec{\omega}$ trophia myotonica. J Med Genet 1972;9:311-5.

10 Grimm T. The age of onset and the age of death in $i v$ patients with dystrophia myotonica. J Genet Hum 1975; 23:301-8.

11 Webb D, Mathews A, Harris M, et al. Myotonia dys- 을 trophica: unusual features in a Labrador family. Can Med Assoc J 1978;118:497-500.

12 Harper PS. Myotonic dystrophy. Philadelphia, London, Toronto: Saunders, 1979.

Requests for reprints to Dr S Bundey, Department of Clinical Genetics, Birmingham Maternity Hospital, Edgbaston, Birmingham B15 2TG. 